\title{
Theorizing written feedback as a mediation tool within the Sydney School's genre pedagogy: a focus on ZPD and scaffolding
}

\author{
Devo Y Devrim
}

Correspondence: ddevrim@une.edu.au School of Education, University of New England Armidale, Armidale 2351, Australia

\begin{abstract}
Despite the abundance of research on feedback in second language development, there is little agreement on what type of feedback is the most effective. Four perspectives emerge from the literature that investigates feedback, specifically: Second Language Acquisition (SLA), Second Language Writing (L2W), Sociocultural Theory (SCT) and the Sydney School's genre pedagogy. The SLA and L2W approaches investigate the effectiveness of corrective feedback, the SCT and the Sydney School perspectives explore feedback as a supportive mediation tool. However, both corrective and supportive types of feedback gain importance in 22 literacy development. Therefore, this paper aims to categorise written feedback as a corrective and supportive tool drawing on the Sydney School's genre pedagogy. An analysis of the feedback instances indicates that written feedback is more effective when it is cast in relation to students' ZPD. The categorization presented in this paper offers a rich framework for $L 2$ writing instructors, as it situates written feedback as a mediation tool based on the related notions of ZPD and scaffolding.
\end{abstract}

Keywords: Written feedback; Response to feedback; ZPD; scaffolding; L2 writing development; Academic literacy; Grammatical metaphor; The Sydney School

\section{Introduction}

This paper aims to explore how written feedback can be theorized as a mediation tool based on Vygotsky's (1978) notions of scaffolding and ZPD. There is abundance of literature regarding the role of corrective feedback in relation to second language development. The research studies that explore the effectiveness of corrective feedback focus on the idea that error correction leads to language development. Although most of the research studies conducted in this field highlight the role of corrective feedback in second language development, they consider written feedback as a corrective tool within the authority of the teacher. However, it is also possible to consider written feedback as a mediation tool between the teacher and students. Therefore, this paper aims to summarize research conducted in the field of academic literacy and argues for more effective written feedback options with examples from an English as a second language (ESL) context. In order to do this, the paper discusses the theorization of written feedback by four different areas of interest, namely, Second Language Acquisition (SLA), Second Language Writing (L2W), Sociocultural Theory (SCT) and systemic 
functional linguistics (SFL) based genre pedagogy of the Sydney School. The discussion of the SLA, L2W, and SCT approaches will be followed by an elaboration on why the Sydney School is productive for understanding second language acquisition and second language writing. SCT and the Sydney School see feedback as a supportive dialogic process between the teacher and the learner. On the other hand, SLA and L2W perspectives regard feedback as a means to correct student errors. The approach presented in this paper helps L2 writing instructors consider written feedback as a corrective and supportive tool that assists to mediate learning. Following the exploration of feedback from these four perspectives, the paper will present a newer theorization of feedback and students' response to written feedback followed by examples.

\section{Background}

The role of feedback in SLA and L2W

SLA and L2W research has led to an extensive body of work in relation to the role of feedback. Feedback in SLA research and L2W is defined as "corrective feedback" and can be either implicit or explicit. According to Kregar (2011: 3), "corrective feedback is any type of oral or written comment, information or question provided to learners that indicates that there is an error in their usage of the L2". The SLA and L2W perspectives to feedback can be discussed in relation to two influential early publications that minimized the role of feedback in L2 teaching (Krashen 1982; Truscott 1996), and may have constrained possible advances in understanding the role of feedback in the ELT profession. The two main publications that discounted the role of feedback were Krashen's (1982) Principles and practices in second language acquisition and Truscott's (1996) The case against grammar correction in L2 writing classes. However, these two publications resulted in a new wave of research that underscored the role of feedback in L2 teaching.

Krashen (ibid.) believed that language acquisition did not require explicit teaching of language or grammar, or drills, and that sufficient comprehensible input was enough to trigger language development. Krashen's input hypothesis theorized language acquisition in relation to comprehensible input and dominated the area of SLA. As a result, Krashen believed that error correction did not have a place in SLA. The reason for this was that he considered language acquisition as a natural process that takes time and error correction could hinder this natural process (Krashen ibid.). Thus, in the immediate aftermath of his work, researchers' attention on the role of feedback was minimal.

Similarly, Truscott (ibid.) called for an abolition of all corrective feedback. However, contrary to this proclamation, Truscott's paper resulted in a new wave of research that started serious investigation into the role and efficacy of feedback contrary to his claims (see Russell and Spada 2006 for meta-analysis of feedback research). These studies show that corrective feedback is effective in the acquisition of grammatical structures, e.g. use of articles and prepositions. While some of these studies posited (e.g. Ellis et al. 2008) that direct feedback is more effective than indirect feedback, others explored the effectiveness of indirect corrective feedback (e.g. Ferris 2010).

The types of feedback from the SLA and L2W perspectives are categorized by Ellis (2009). Feedback types are classified in relation to feedback being direct, indirect, metalinguistic, focused versus unfocused, electronic and reformulation. Table 1 presents 
Table 1 Types of feedback (adapted from Ellis ibid.: 97-98)

\begin{tabular}{|c|c|}
\hline Feedback strategy & Description \\
\hline Direct corrective feedback & Teacher provides the correct form \\
\hline Indirect corrective feedback & $\begin{array}{l}\text { Teacher tells the students that there is an error, but doesn't correct it. } \\
\text { This may or may not include locating the problem (via underling etc.). }\end{array}$ \\
\hline $\begin{array}{l}\text { Metalinguistic corrective } \\
\text { feedback }\end{array}$ & $\begin{array}{l}\text { Teacher gives metalinguistic clues to students to help them understand } \\
\text { the nature of the problem. This can be done by using error codes or } \\
\text { by providing brief grammatical descriptions. }\end{array}$ \\
\hline Focus of feedback & $\begin{array}{l}\text { Teacher can choose to provide feedback on selective errors (called } \\
\text { focused or intensive feedback), or provide feedback on all (or most) } \\
\text { errors (called unfocused or extensive feedback). }\end{array}$ \\
\hline Electronic feedback & $\begin{array}{l}\text { Teacher highlights the error and provides a hyperlink that provides } \\
\text { additional information about the error. }\end{array}$ \\
\hline Reformulation & Teacher rewrites students' text. \\
\hline
\end{tabular}

various types of corrective feedback that summarizes research from SLA and L2W perspectives.

Table 1 Types of feedback (adapted from Ellis ibid.: 97-98)

As shown in Table 1, these classifications are based on corrective written feedback targeting graphology and lexicogrammatical features; however, language development covers a larger area including content, organization, word choices, registerial effectiveness, lexicogrammar and grammatical metaphor (see Devrim 2013; 2012). Therefore, the perspective that theorizes feedback should also include linguistic areas that are above grammar and morphology.

Also, Ellis's (ibid.) feedback categorisation does not deal with the supportive feedback that this paper aims to explore. Table 1 categorizes feedback in relation to error correction only. However, this approach needs to be developed to include supportive feedback with the aim of eliciting correct and/or more appropriate text revisions from students. Another limitation of the categorization is that, it is based on the idea that the "nativespeaker" is the ultimate provider of feedback, which draws on Chomsky's (1965) suggestion to consider "native-speaker" as the ideal speaker and hearer. However, being a proficient feedback provider is a result of language expertise rather than language heritage. The assumption that the "native-speaker" is superior to the "non-native" speaker in feedback provision is not supported by evidence.

\section{Role of feedback in SCT}

The third approach to feedback, SCT, draws on Vygotsky's (ibid.) notions of mediation, scaffolding and ZPD. The feedback in SCT is regarded as a dialogic process between teachers and students (Lantolf 2006). In an earlier work, Aljaafreh and Lantolf (1994: 480) posit that,

Effective error correction and language learning depend crucially on mediation provided by other individuals, who in consort with the learner dialogically co-construct a zone of proximal development in which feedback as regulation becomes relevant and can therefore be appropriated by learners to modify their interlanguage systems.

Such collaboration means that students are not supplied with indirect or direct feedback within an SCT approach. Feedback in such an approach is not concerned with 
providing the correct form or bringing errors to students' attention. Instead, the focus is on the ability to shunt between more implicit and explicit feedback depending on the ZPD of students. Drawing on SCT, the next section aims to theorize written feedback as a mediation tool based on the notions of scaffolding and ZPD by presenting two topologies: one for written feedback, another one for students' response to feedback.

\section{Role of feedback in the Sydney School}

The approach to feedback in this paper adopts the Sydney School's genre pedagogy, which shows similarities to Vygotsky's (1978) notions of scaffolding and ZPD. Genre pedagogy of the Sydney School is considered explicit due to the goal of making academic literacy demands explicit so that all the students have access to linguistic resources required for success. It is also considered visible because the pedagogy is based on explicitly defined learning and teaching roles for teachers and students. The pedagogy follows the teaching learning cycle (TLC) where the teacher presents a model text and deconstructs it, and then, the students work with the teacher to compose the same text type, and are given the opportunity to compose the same text on their own (Rothery 1994). Therefore, feedback is a rather important tool in the Sydney School's genre pedagogy, and its importance is emphasized by Ken Hyland (2007, p. 160):

A key purpose of the cycle is to ensure repeated opportunities for students to engage in activities which require them to reflect on and critique their learning by developing understandings of texts, acting on these through writing or speaking, reviewing their performance, and using feedback to improve their work.

The approach to feedback in Sydney School's genre pedagogy provides a richer framework and more opportunities for learning, as it is different from the notion of feedback in the SLA and L2W approaches. The SLA and L2W approach focus feedback on the clause level and correction only (see Ellis 2009; Ferris 2010). However, the analysis of feedback needs to focus on various language levels, including genre, register, discourse semantics, lexicogrammar and graphology. Furthermore, the Sydney School focuses on corrective and supportive feedback, as the fundamental goal is to scaffold students (Devrim 2013). Drawing on the Sydney School, the next section aims to theorize written feedback as a mediation tool based on the notions of scaffolding and ZPD. It does so by presenting two topologies: one for written feedback, another one for students' response to feedback.

\section{Methods}

The data for this paper comes from Devrim's (2013) Ph.D. research. The research was conducted as part of the SLATE (Scaffolding Literacy in Adult and Tertiary Environments) Project. The SLATE project aimed to improve academic literacy skills of undergraduate students who were enrolled at a university in Hong Kong. While the SLATE project investigated the role of written feedback at a more general level, Devrim (2013) explored the feedback provided by tutors, who were based in Sydney, targeting experiential and logical metaphors. The data for this paper are extracted from students' assignments. To be able to observe whether there was improvement in students' GM use, all the submitted draft assignments were tracked.

The analytical framework adopted in this project is based on the theorization of GM in SFL. The GM model that was adopted for the purposes of this action research 
project was based on Halliday $(1985,1988,1993)$, Martin $(1992,1993)$ and Halliday and Martin (1993). Halliday and Martin theorize and exemplify GM based on "stratal tension" between discourse semantics and lexicogrammar (see Devrim 2013).

Secondly, the feedback instances targeting GM use were categorized according to their explicitness depending on whether there is one correct/appropriate option or there are multiple correct/appropriate options. Furthermore, feedback was also categorized whether tutors provided the students with rationale as to why suggested changes were necessary by giving examples, explaining the reason behind suggestions, and directing students to support material.

\section{Written feedback topology}

Written feedback will be analysed using a topology which provides how different feedback types relate to each other. A topology is more relevant to the needs of L2 writing instructors in the sense that it provides a more interrelated categorization of feedback. Therefore, it is more applicable to language teaching in comparison to a typology.

The feedback topology consists of four quadrants in relation to the explicitness level of feedback and provision of rationale. Furthermore, the level of explicitness and the provision of rationale are surrounded by a shared metalanguage. The feedback instances that were framed explicitly without rationale were referred to as carrying, which is similar to a situation where a parent carries a baby. The second quadrant was considered hand holding where the students were provided with a rationale, which is similar to a situation where a parent holds hands with their child. The third quadrant was titled bridging where the tutors provided less explicit feedback with rationale. This category is similar to parents building a bridge for their child to cross over. The fourth quadrant is named free climbing where the tutors simply asked students to make changes implicitly without providing any rationale, which reminds one of free climbing where the child climbs up a boulder without using ropes. Figure 1 illustrates how the explicitness of feedback and the provision of rationale relate to each other within the boundaries of a shared metalanguage.

Figure 1 Topology of feedback within metalanguage (Devrim 2013: 216)

Figure 1 shows the categorization of feedback based on explicitness and provision of rationale. The explicitness of feedback is given in a cline ranging from more explicit to less explicit. However, explicitness in my context refers to one correct or more appropriate option suggested by the tutors. The explicit feedback, thus, tells students what to do exactly. On the other hand, implicit feedback aims to elicit a correct or more appropriate option from students. In this case, tutors do not tell students what to do. Instead, students are encouraged to come up with improved text sections using their linguistic repertoire.

The rationale axis in Figure 1 refers to the ways in which the tutors chose to tell a student how a text section would be improved based on a suggested change, to show how to revise a text section or to direct students to support documents. Furthermore, these feedback instances provide the students with information on how the change would improve their assignments or how to manage the change by providing students with clues. The language feedback provided with rationale as to why a particular 


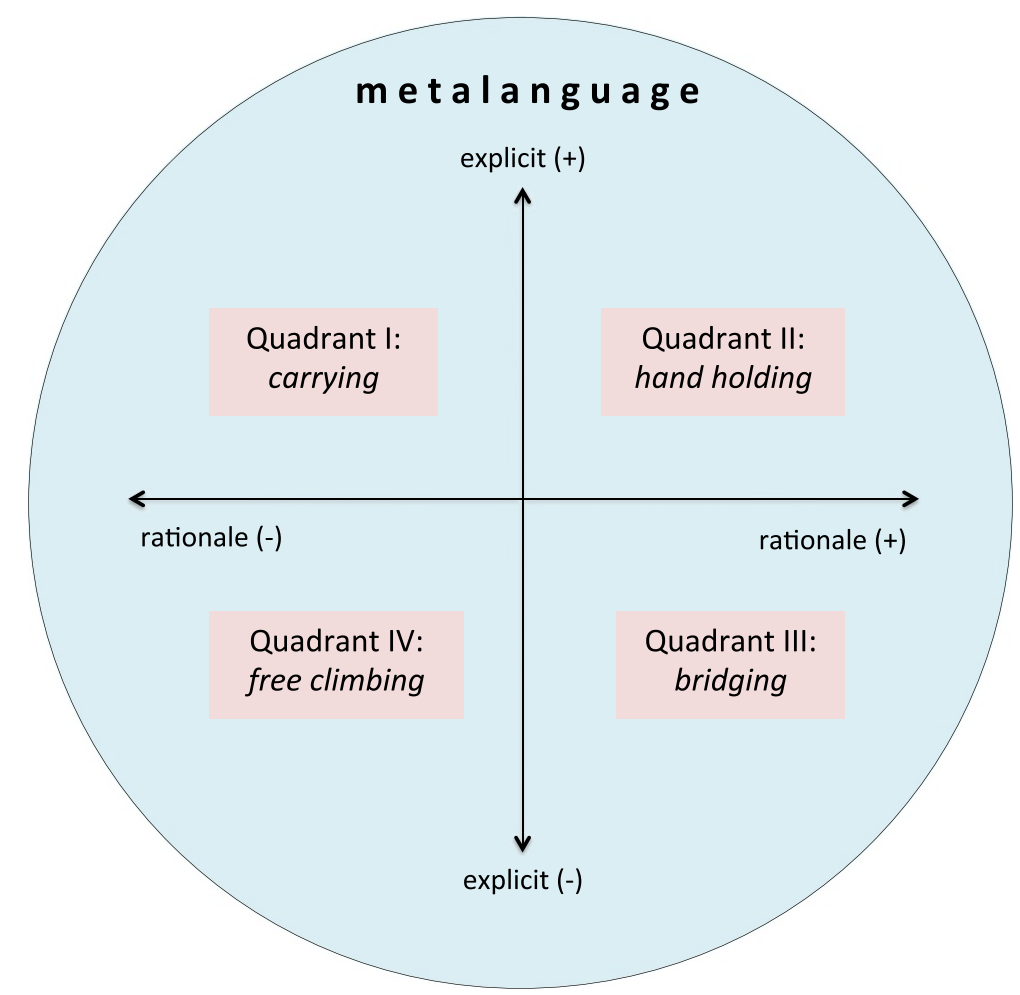

Figure 1 Topology of feedback within metalanguage (Devrim, 2013: 216).

change is required is grounded in students' ZPD and framed in relation to student language proficiency (Devrim 2013; Mahboob and Devrim 2012).

\section{Response to feedback topology}

Similarly, students' responses to feedback is analysed using another topology to present how different choices relate to each other. The response to feedback topology also consists of four quadrants in relation to $(+/-)$ uptake and (+/-) full in order to explore how mediation takes place between tutors and students. Figure 2 shows the possible ways that students respond to written feedback.

\section{Figure 2 Students' response to written feedback}

As shown in Figure 2, the topology builds on two axes: $(+/-)$ uptake and $(+/-)$ full, comprising of four quadrants. The first quadrant is labelled attempting, where the uptake is positive, but completeness is negative. This is the response type where students make changes based on the written feedback they have received. However, the revised version of the text does not make full use of the feedback, thus, the revised text section either contains a grammatical mistake or does not satisfy the feedback. The second quadrant is called succeeding, where both axes are positive. This is the feedback category where students adopt all of what is suggested in the feedback. The third quadrant is labelled as ignoring. The feedback instances categorized in this quadrant describe the avoidance of feedback where uptake is negative and completeness is positive. This category includes response instances where students ignore the feedback provided. The 


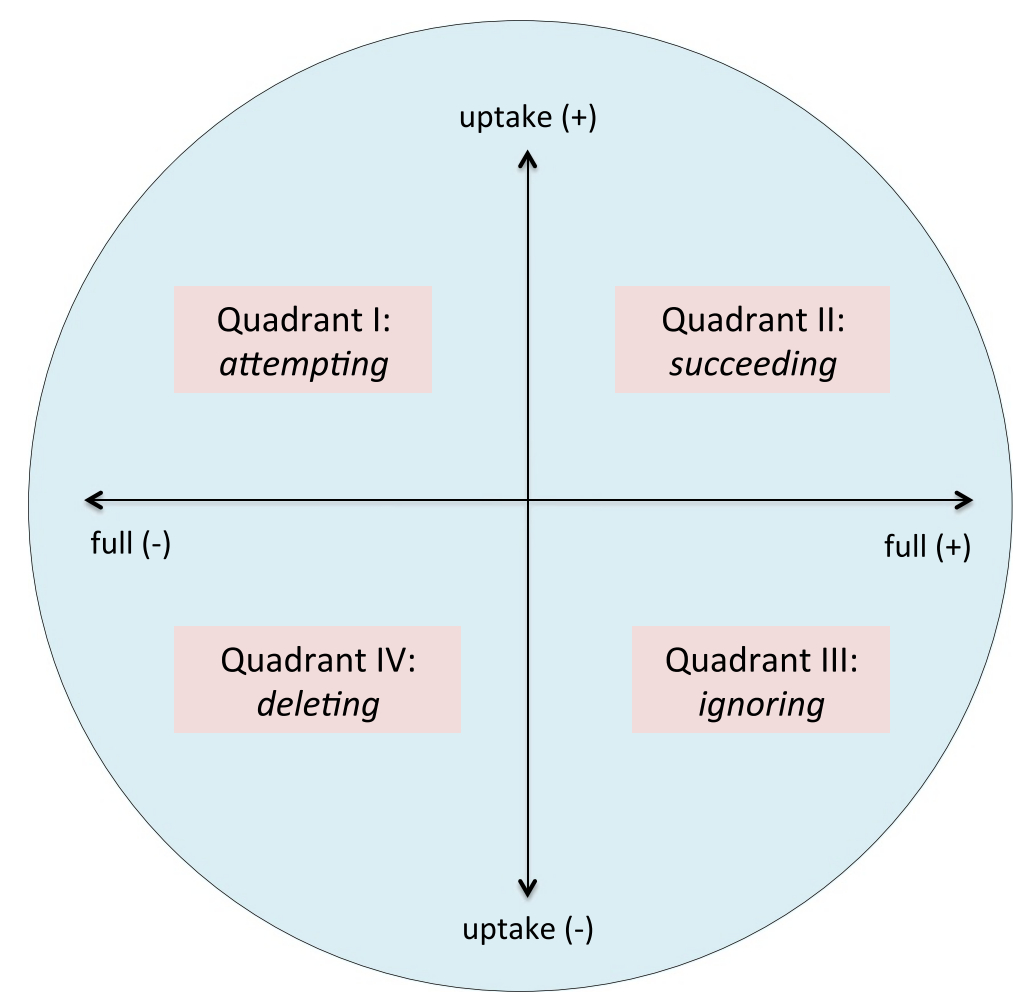

Figure 2 Students' response to written feedback.

last quadrant is named deleting, where the text section targeted by written feedback is deleted. Therefore, the uptake axis is negative and the completeness axis is negative.

\section{Results}

This section will provide some feedback instances. Each instance will be explained in relation to the feedback topology and the mediation between tutors and students will be tracked using the response to feedback topology. The data for this paper comes from a recent doctoral study (Devrim 2013), which aimed to develop an approach to teaching grammatical metaphor (GM) through online written feedback. The feedback instances below are regarding the improvement of students' GM use. GM, which was described by Halliday (1985a), is an important linguistic feature in science, bureaucracy, and academia (Halliday and Martin 1993), so its mastery leads to the development of L2 literacy. GM can be simply defined as non-typical ways of meaning making, e.g. transforming verbs and adjectives into nouns to be able to discuss them as facts, and managing causality within clauses rather than using conjunctions between clauses. Specifically, packing information into noun groups is considered experiential metaphor, and construing causality within a clause is regarded as logical metaphor (Martin 1992). Experiential and logical metaphors help students organize their texts in a more logical way, as well as help them reach a higher level of academic literacy skills.

There are two sets of feedback instances in this section. The first set investigates how mediation is accomplished in relation to the ZPD of students. The second set, on the other 
hand, explores how feedback is mediated across drafts. The feedback instances in the following examples are in italics and cast in curly brackets, and students' revisions are in bold face.

\section{Feedback to different students}

The first set of examples is presented in relation to the feedback topology. Firstly, the feedback type will be identified, and then students' next draft will be investigated to observe how they respond to feedback. In the whole data set, less proficient students were provided with more instances of explicit feedback; whereas, proficient students received more instances of implicit feedback.

\section{Example 1}

The first instance of feedback was framed explicitly without a rationale that explains the process or why revision is necessary, which belongs to the carrying category.

Example 1a Lastly, the $0.1 \mathrm{~K}$-ohm resistor converts the current to voltage, enabling us to measure \{You could use the grammatical metaphor in this spot e.g.: the measurement of... the output voltage across it.

In Example 1a, the student uses the infinitive form of the verb "measure" while introducing resistor. The tutor thinks this is an appropriate text section to use GM. So, he/ she suggests the student use "the measurement of ...". The student revises the sentence based on the feedback.

Example 1b (response in draft 2) Lastly, the $0.1 \mathrm{~K}$-ohm resistor converts the current to voltage, enabling the measurement of the output voltage across it.

The suggestion from the tutor "the measurement of ..." is used for text revision. Furthermore, the student deletes "us" following the verb "enable". This suggests that the student is knowledgeable regarding the requirements of academic register and deletes the personal pronoun. Therefore, this instance of response is categorized belonging to the succeeding quadrant.

\section{Example 2}

This feedback instance provides the student with the desired form with rationale. Therefore, it belongs to the hand holding category.

Example 2a A Zener diode allows current flow in the forward direction like a normal diode, but also in the reverse direction if the voltage is larger than the breakdown voltage known as a "zener voltage". So \{we usually use 'so' in speaking in the beginning, but in academic writing it would be better to use sentence linkers such as 'therefore' or 'thus'. You may also try to use some of grammatical metaphors: This results in limiting the input voltage ... and by doing so you will have the same focus in the sentence and would not need to use 'by the zener diode') the input voltage is limited from $10 \mathrm{~V}$ to 6.8 by the zener diode.

As can be seen in Example 2a, the tutor provides feedback on GM use by providing clues to the student. Interestingly, the way this is done requires the use of three GM instances. Firstly, "this" is a demonstrative that replaces nominalization, and it is followed by a logical metaphor in the form of a verb, "results". The process needs to be followed 
by another GM. This is an experiential metaphor in the form of an INGnominalization. The student makes revisions to the original sentence.

Example 2b (response in draft 2) This results in limiting the input voltage from $10 \mathrm{~V}$ to 6.8. In order to amplify the input current, two 2 N3055 NPN power transistors are compounded together to form a Darlington pair.

The revised text section starts with the suggestion and the student manages to form a grammatically accurate sentence. Therefore, this response to feedback belongs to the succeeding quadrant.

\section{Example 3}

This following instance of feedback is categorized as bridging, as there is not only one way to form a grammatically accurate sentence, and rationale is provided as well.

Example 3a First of all, nominalization helps compacting (Why don't you try to use some nominalization here? By removing the processes from this sentence, you can realize some of the changes you discuss. \} information.

The tutor casts implicit feedback with rationale and uses "nominalization" as metalanguage. In the original text, the student uses ING-nominalization, "compacting" in a topic sentence to introduce the first effect of nominalization on language. The way this is done also requires the use of a logical metaphor, "help". The tutor provides feedback at this point, asking the student to use nominalization that would help remove the processes from the sentence.

Example 3b (response in draft 2) First of all, the compactness of text will be improved by using nominalization.

The student uses an experiential metaphor in the nominalization form, by transforming the verb "compacting" to the noun "compactness". Also, he/she includes a logical metaphor using the preposition "by", and another experiential metaphor, "using". Because the student makes changes that result in GM use and a grammatically accurate clause, his response to feedback is considered succeeding.

\section{Example 4}

The final feedback in this section is categorized as free climbing. It is implicit and no rationale is provided.

Example 4a Error is something that cause the experiment result not in accuracy and not in precise. They will appear in any areas like the instrument, the environment and personal. There are several uncertainty would be found in this experiment. \{See if you can condense this information to one sentence that introduces the idea that various errors can occur in the experiment?.

In Example 4a, the tutor wants the student to condense the information into one sentence. Combining two clauses into one requires the use of a logical metaphor. The tutor does not tell the student how to do it; instead, the student is just told to form one clause to condense the meanings into one clause. 
Example 4b (response in draft 2) There are several errors would be found in the experimental instrument and environment which cause the experiment result not in accuracy and not in precise.

The student manages to form one sentence by changing the places of a few phrases. The way the student uses the verb "cause" in the revised version is a logical metaphor, as it logically connects the "errors" to "inaccuracy". Although the student benefits from the feedback instance, the revision does not result in a grammatically accurate sentence. Thus, the student's response to feedback belongs to the attempting quadrant.

\section{Feedback to a single student}

The second set of examples addresses how mediation is accomplished across drafts. The first feedback instance is implicit, and it does not result in succeeding. However, the tutor follows up with more explicit feedback in the following draft.

Example 5a Therefore comparing the data with the theoretical and checking whether the equation is right or not (Can you think of a noun that refers to whether something is accurate or not? A word like this would sound more technical than whether $\mathrm{x}$ is right or not\} become an important precaution of the experiment.

In Example 5a, the tutor asks the student to come up with a noun to refer to if something is accurate or not. The tutor wants to elicit the word from the student by providing clues without the correct form. Therefore, this feedback instance belongs to the bridging quadrant, as it provides a rationale.

Example 5b (response in draft 2) Therefore, comparing the data with the theory and checking whether the experimental result is accurate or not become an important precaution of the experiment.

In the second draft, the student revises the sentence by using "accurate or not". The student copies "accurate or not" from the clues provided. The response belongs to the attempting category, as it does not result in full uptake. Therefore, the tutor provides another instance of feedback on the same text section in draft 2 .

Example 5c (feedback in draft 2) Therefore comparing the data with the theory and checking whether the experimental result is accurate or not \{use nominalization "the accuracy of ...." This will improve the sentence, making more formal and academic\} become an important precaution of the experiment.

Unlike the feedback provided in 5a, the tutor provides more explicit feedback, telling the student what to do. In this instance, the tutor is explicit about how the suggested change will improve the text, providing a rationale for why such a change is necessary. Therefore, the feedback instance belongs to the hand holding category.

Example 5d (response in final submission) Therefore, comparing the data with the theory and checking the accuracy of the experimental results become an important precaution of the experiment. 
Due to the tutors' follow-up feedback, the student uses the phrase "the accuracy of" and also manages to place the suggested phrase within the clause. Thus, the student's response belongs to the succeeding quadrant.

\section{Discussion}

The above categorization of written feedback and response to feedback opens up a discussion regarding appropriate types of feedback. The theorization of feedback in this paper situates written feedback as a mediation tool, which aims to correct and support student writing. There are two reasons why this theorization is more robust than the feedback perspective by SLA and L2W.

The first issue concerns the best feedback provider. According to Ellis, this should be a native speaker of English. Ellis states "... in order to identify an error, the analyst (and the teacher) needs to construct a native- speaker version of that part of the text containing an error" (op.cit.: 103). That is, the teachers who provide corrective feedback should be "native speakers" of English based on the assumption that "non-native teachers" of English are not fully proficient to help students' improve their writing skills according to this view. However, providing writing feedback cannot only be based on the "native-speaker" model, "non-native" speakers can also provide effective written feedback. This underscores the importance of expertise over language heritage. In order to reach a more appropriate categorization of feedback, this paper investigates feedback provided by "native" and "non-native" speakers of English.

Secondly, the feedback model proposed in this paper offers more in comparison to SLA and L2W perspectives. These two perspectives focus on corrective feedback and research the effectiveness of direct or indirect corrective feedback at clause level. In this paper, two ways of providing written feedback on GM were discussed. The first one concentrated on providing support to students based on their ZPD. The feedback topology categorized feedback from more explicit to less explicit. The more explicit feedback (carrying and hand holding categories) appeared to work well with less proficient students who need explicit scaffolding. On the other hand, implicit feedback (bridging and free climbing categories) works well with proficient students. Therefore, L2 writing instructors should determine the proficiency levels of students before providing them with feedback not only to be able to provide the appropriate level of explicitness of feedback, but also to track development of students across subsequent drafts. Aljaafreh and Lantolf (op.cit.: 468) state that,

Determining a learner's ZPD is an act of negotiated discovery that is realized through dialogic interaction between learner and expert. In other words, the learner and expert engage each other in an attempt to discover precisely what the learner is able to achieve without help, and what the learner can accomplish with assistance... Importantly, the help negotiated between the novice and expert is graduated and contingent in the sense that it moves from more explicit to more implicit, or strategic levels, and is offered only when needed and is withdrawn once the novice shows signs of self-control and ability to function independently.

From the SCT perspective to feedback, there are two important issues that L2 writing instructors should pay attention to. The first one is determining learners' ZPD. Determining learners' ZPD requires language teachers to differentiate between proficient and 
less proficient writers. This, in turn, will help teachers situate their written feedback more explicitly or implicitly depending on the ZPD of students. Secondly, L2 writing instructors should be able to make their written feedback more explicit, if implicit feedback does not result in student uptake in a subsequent draft. The theorization of written feedback in this paper aims not only to provide academic writing instructors with a framework that would be helpful in casting their feedback according to students' ZPD, but it will also help provide more explicit feedback in subsequent drafts, if implicit feedback does not work.

\section{Conclusion}

This paper investigated how written feedback can be theorized as a mediation tool based on Vygotsky's (1978) notions of scaffolding and ZPD. To reach this aim, the paper discussed four approaches to feedback. The first one was SLA, which was followed by L2W. Both of these approaches investigate the role and effectiveness of corrective written feedback. On the other hand, the SCT and the Sydney School approaches, which are quite closely relate to each other, explore feedback as a mediation tool to correct and as well as support students. While the SCT approach focus on oral language development, the Sydney School approach research written language development. The feedback instances presented in this paper were analyzed using two topologies; the feedback and students' response to feedback topologies. The paper concluded with a discussion section as to why the theorization of written feedback presented here is more productive in understanding literacy development as opposed to the other approaches.

\footnotetext{
Abbreviations

SLA: Second Language Acquisition; L2: Second language; L2W: Second Language Writing; SCT: Sociocultural Theory; SFL: Systemic functional linguistics; ZPD: Zone of proximal development.

Competing interests

There are no competing interests.

\section{Acknowledgements}

This paper is based on work from the Scaffolding Literacy in Tertiary and Adult Environments (SLATE) Project, between the University of Sydney and the City University of Hong Kong. The chief investigators were Jim Martin, Ahmar Mahboob, Shoshana Dreyfus, and Sally Humphrey. I would like to express my gratitude for Jim Martin, Ahmar Mahboob, Shoshana Dreyfus and Sally Humphrey for sharing their knowledge and expertise with me. The views expressed herein are those of mine.

I would also like to thank my colleague Mary Macken-Horarik for her suggestions and comments on earlier versions of this paper.
}

Received: 29 January 2014 Accepted: 6 August 2014

Published online: 22 August 2014

\section{References}

Aljaafreh, A, and JP Lantolf. 1994. 'Negative feedback as regulation and second language learning in the zone of proximal development'. The Modern Language Journal 78:465-483.

Chomsky, N. 1965. Aspects of the Theory of Syntax. Cambridge, MA: MIT Press.

Devrim, DY. 2013. 'Development of grammatical metaphor in academic literacy through online language support'. Australia: University of Sydney. Unpublished PhD thesis.

Devrim, DY. 2012. 'Developing an approach to teaching grammatical metaphor'. In ISFC 39 Conference Proceedings: 45-50. Australia: University of Technology Sydney.

Ellis, R. 2009. 'A typology of written corrective feedback types'. ELT Journal 63(2):97-107.

Ellis, R, Y Sheen, M Murakami, and H Takashima. 2008. The effects of focused and un-focused written corrective feedback in an English as a foreign language context'. System 36:353-371.

Ferris, DR. 2010. 'Second language writing research and written corrective feedback in SLA: Intersections and practical applications'. Studies in Second Language Acquisition 32:181-201.

Halliday, MAK. 1985. Introduction to Functional Grammar. London: Arnold.

Halliday, MAK. 1988. On the language of physical science. In Registers of written English, ed. M Ghadessy. London: Pinter.

Halliday, MAK, and JR Martin. 1993. Writing science: Literacy and discursive power. London: The Falmer Press. 
Hyland, K. 2007. Genre pedagogy: Language, literacy and L2 writing instruction. Journal of Second Language Writing 16(3):148-164.

Krashen, SD. 1982. Principles and Practices in Second Language Acquisition. Oxford: Pergamon Press.

Kregar, S. 2011. 'Relative effectiveness of corrective feedback types in computer-assisted language learning'. U.S.A.: The

Florida State University. Unpublished PhD thesis.

Lantolf, JP. 2006. 'Sociocultural Theory and L2: State of the art'. Studies in Second Language Acquisition 28(1):67-109.

Mahboob, A, and DY Devrim. 2012. Supporting independent construction online: Feedback in the SLATE project'.

Linguistics and Human Sciences 7(1-3):101-123.

Martin, JR. 1992. English text: System and structure. Amsterdam: John Benjamins.

Martin, JR. 1993. Technology, bureaucracy and schooling: Discursive resources and control. Cultural Dynamics 6(1):84-130.

Rothery, J. 1994. Exploring Literacy in School English (Write it Right Resources for Literacy and Learning). Sydney: Metropolitan East Disadvantaged Schools Program.

Russell, J, and N Spada. 2006. The effectiveness of corrective feedback for the acquisition of L2 grammar: A meta-

analysis of the research'. In Synthesizing Research on Language Learning and Teaching, ed. J Norris and L Ortega,

131-164. Amsterdam: John Benjamins.

Truscott, J. 1996. 'The case against grammar correction in L2 writing classes'. Language Learning 46:327-369.

Vygotsky, L. 1978. Mind in Society: The Development of Higher Psychological Processes. London: Harvard University Press.

doi:10.1186/s40554-014-0008-z

Cite this article as: Devrim: Theorizing written feedback as a mediation tool within the Sydney School's genre pedagogy: a focus on ZPD and scaffolding. Functional Linguistics 2014 2:8.

Submit your manuscript to a SpringerOpen ${ }^{\circ}$ journal and benefit from:

- Convenient online submission

- Rigorous peer review

- Immediate publication on acceptance

- Open access: articles freely available online

- High visibility within the field

Retaining the copyright to your article

Submit your next manuscript at $\boldsymbol{\sim}$ springeropen.com 